\title{
Using 'voice' to understand what college students with intellectual disabilities say about the teaching and learning process
}

\author{
John Kubiak \\ Trinity College Dublin, Ireland
}

Key words: Pupil voice, teaching and learning strategies, people with intellectual disabilities, higher education.

\begin{abstract}
There is a growing awareness of the value of using pupils' voices in educational research. At primary and second level, the principle of pupil voice has gained in profile over the last decade. However, in higher education, the use of voice in research collaborations remains under-theorised and under-utilised. This paper reports on an inclusive phenomenographic study undertaken with college students with intellectual disabilities (ID). It outlines how pupil voice can be used to gain a deeper understanding of the teaching and learning process. The strategies that promoted learner engagement and autonomy include establishing a supportive learning climate or environment, and promoting self-regulated learning strategies. These findings suggest that the use of pupil voice is fundamental to changing the way teachers think about students with ID and their learning.
\end{abstract}

\section{Introduction}

The Convention on the Rights of Persons with Disabilities (UNCRPD) has been one of the main catalysts for the drive in promoting the rights of people with disabilities to express their opinions on matters affecting their lives (United Nations, 2006). The right to primary and secondary education, vocational training, adult education and lifelong learning as articulated in Article 24 of this convention is a channel to not only the inclusion in education, but also to independent living and competitive employment for people with intellectual disabilities (ID) (see also the Salamanca Statement on Principles, Policy and Practice in Special Needs Education; UNESCO, 1994).

In response to this convention and to the growing need of people with ID to access higher education opportunities, an increasing number of tertiary educational programmes have come into existence both nationally and internationally for this group of individuals (see Saloviita, 2000; Flinders University, 2011; Uditsky and Hughson, 2012; University of Alberta, 2006; Hart et al., 2006).
In the Republic of Ireland, the numbers of third-level courses for people with ID have also grown. The first full-time course entitled the Certificate in Contemporary Living (CCL) (see Kubiak and Espiner, 2009; O'Brien et al., 2008; O'Connor et al., 2012) was established at the National Institute for Intellectual Disability (NIID) Trinity College Dublin in 2005 and is now the longest running course of its kind in Ireland. The NIID also has a research agenda that promotes participatory action research (PAR; see Chadwick et al., 2010) and inclusive research (see Kubiak, 2013; National Institute for Intellectual Disability, 2010). The aim of these collaborative approaches is to allow the 'voice' of people with ID to emerge so they can exert some control over the process, the outcomes and the dissemination of the research project.

The emergence of voice in primary- and second-level education

Flutter (2007) argues that the basic premise of the student (or pupil) voice is that 'listening and responding to what pupils say about their experiences as learners can be a powerful tool in helping teachers to investigate and improve their own practice' (p. 344). The principle of 'voice' and in particular 'pupil voice' has gained in profile over the last decade, and many countries have introduced pupil consultation and participation into their educational systems. This can become an important catalyst for change as it encourages teachers to reflect on what happens in the classroom; it also encourages practitioners to 'see the familiar differently and to contemplate alternative approaches, role and practices' (Rudduck and Flutter, 2003, p. 141).

Pupil voice therefore affords educators an opportunity to focus their attention on what really matters - learners and how they learn. Studies undertaken in the school context, which focused on teaching and learning (for examples see Rose and Shevlin, 2010; Rudduck and Flutter, 2003), have illustrated the positive dimensions of pupil voice and how it can be used to support teachers' development. The transformative potential of pupils' voice is well documented in the research by Pedder and McIntyre (2004); Cooper and McIntyre (1996); and Flynn, Shevlin and Lodge (2012). 
Other examples of students' voice include: pupils as researchers (Fielding and Bragg, 2003); pupils helping other students with their learning (Topping, 2001), and assessment for learning approaches (Black et al., 2002). What these and other studies have shown is that one of the most interesting aspects of pupils voice research lies in its power to "unlock the shackles of habit that so often bind teachers to their familiar routines of practice and thought' (Flutter, 2007, p. 352). This process has the potential to allow new insights to be gained into the factors that make a difference to pupils' learning and progress.

\section{The issue of power in voice and research}

According to Foucault (1980), power is relational, situated, circulated, endlessly negotiated and constructed; it is neither an entity to be possessed or given away, nor is it inherently negative and solely vertical. Some researchers (i.e., de los Reyes and Gozemba, 2002) counter the myth of student powerlessness and assert that it is the lack of opportunity to experience their own power that prevents them from regaining their place as active social actors in their schools and communities. A number of typologies (for example, Hart, 1992 and Fielding, 2004) have been applied in student voice to describe the extent of power in relation to student involvement and influence in decisionmaking. For example, Hart (1992) outlines eight levels of involvement that ranges from 'non-participation' (manipulation and tokenism) to a gradual increase in participation that culminates in the highest level of child initiated shared decisions with adults. Vital to this framework is the manner in which children/students are positioned in relation to adults which allows the nurturing of students' developing capacities to emerge through cooperation with adults.

In a similar vein over the last decade, people with disability have increasingly become involved in research projects with an aim to create a more balanced partnership between researchers without disabilities and research participants with disabilities (Traustadóttir, 2006). New approaches to research have begun to appear under the rubric of inclusive research (Walmsley and Johnson, 2003) and PAR (Chappell, 2000; Reason and Bradbury, 2006). These approaches denote research in which people with disabilities are active shapers of the research rather than passive research subjects. Inclusive research is closely related to participatory and emancipatory influences (Barnes, 2004), the latter having strong connections with the social model of disability and the movement of people with disability in the UK (Björnsdóttir and Svensdóttir, 2008). PAR covers a welter of approaches and applications in research and is described by Turnbull, Friesen and Ramirez (1998) as having six levels of stakeholder participation that illustrate an ever-increasing extent of stakeholder decision-making related to the research enterprise. These include 'Stakeholders as research participants' at the lowest level to 'Stakeholders as research leaders and researchers as ongoing advisers' at the highest level.
Although the active engagement of students' voice in research has been a practice in the field of school-based enquiry, research collaborations with students in higher education, however, remains 'under-theorised and underutilised' (Kirshner and O'Donoghue, 2001, p. 4). Addressing this concern, the following section outlines the results of an inclusive research study undertaken with college students with ID and outlines how student voice was used to gain a deeper understanding of the teaching and learning process.

\section{Methodology}

This qualitative research was conducted as fieldwork for a thesis that built on current descriptions of phenomenographic approaches to educational research (i.e., Marton and Booth, 1997; Marton and Tsui, 2004) and elements of inclusive research (Walmsley and Johnson, 2003).

Three main groups of individuals participated in this study: (1) co-researchers with ID (three males and three females, $\mathrm{n}=6$ ), (2) students with ID (eight females and ten males, $\mathrm{n}=18$ ) and (3) this paper's author. Individual semistructured interviews with CCL students were conducted by co-researchers who undertook 11 weeks of training in inclusive research theory, material design and accessibility, presentation skills, interviewing skills and the process of questioning.

Co-researchers used a visual stimulus (i.e., a drawing or a concept map created by the interviewee) to elicit information from their peers (identified in this paper as Participant 1-18 / P1-18). Questions were semi-structured and focused on the question: 'How do you learn in college?' Interviews were transcribed verbatim, and data were analysed using a phenomenographic approach (Åkerlind, 2005; Marton and Booth, 1997). Confidentiality and anonymity in reporting results were guaranteed to all participants.

\section{Findings}

This section presents a selection of the data from the interviews regarding what college students with ID say about learning, and is divided into two sub-sections: (1) the supportive learning environment and (2) self-regulated learning (SRL) - what happens before, during and after learning.

\section{The supportive learning environment}

Learning is a complex task that is dependent on a combination of factors, for example the learner's background, the teaching practices the learner may experience and the learning environment (Dart et al., 2000). The concept of environment, as applied to educational settings, refers to 'the atmosphere, ambience, tone, or climate that pervades the particular setting' (Dorman, 2002, p. 112). Dart et al. (2000) showed the benefits of learning environments that are 'safe, supportive, and that offer helpful relationships' (p. 269). The powerful role the teacher plays in shaping a 
psychological environment that facilitates learning has also been noted by Rix et al. (2009) and Mitchell (2008).

For the following student, a safe classroom space was informed by the class group culture; this space was somewhere where she could feel comfortable to ask questions and share ideas that were about 'important things' (P13) with her classmates: 'Students are just like friends and they are there to support me and I'd do the same for them. . we are a strong group and (together) we're able to ... cope with college' (P13).

The learning environment of the NIID supported another student's individual learning needs; he explained that the material was not beyond him because in this environment 'everything goes on at my own level ... I can understand it ... if you have problems you can ask questions and nobody will start judging you or start smirking' (P11).

For this learner, feeling comfortable in a learning environment meant knowing that other students were not behaving in a judgemental or an antagonistic way. This student felt that the NIID's environment encouraged students to reflect on the agreed group culture and promoting an environment 'where people... who have problems with learning... are able to take everything at (their) own pace' (P11).

For some students, a preferred way to commence a class session was to remind each other of the group culture; this started with each person taking turns to say how they were feeling; it meant 'starting a session with a round' (P6). This following learner felt that it was important to start with a round because it enabled her to offload her own 'good or bad' feelings, and if there were problems emerging within the group, it also offered an opportunity to address this and 'revisit the group culture' (P6). Finally, in the opinion of another student, the sense of 'feeling safe' (P13) was an essential ingredient for learning to unfold: 'You can remember (the information) the teacher is telling you (when) you're in an environment where you feel safe. . You're safe when you're with your friends at college, learning the same thing' (P13).

\section{$S R L$}

For Dorman (2002), one of the five elements of the supportive classroom environment is self-regulation. SRL deals with the learning process, i.e., what happens before, during and after the learning act. Zimmerman (2002, p. 65) points out that the characteristics of a self-regulated learner are not only the ability to prepare and take the essential steps in order to learn in a 'pro-active way', but also have the capability to take care of their own monitoring, motivation and feedback processes, both during and after learning.

Before learning: goal setting. The first phase of SRL is goal setting - what happens before the learning act. Participants of this research recorded what happened before a particular learning act on a planning worksheet that included an outline of short-term goals, such as a groupwork assignment: 'I have a group presentation next Thursday; I need to prepare and meet the group' (P 3), or longer term goals: 'I want to work with children after I finish college' (P8). For one student, having clear goals also formed an essential part of controlling his behaviour - in this particular case, it was avoiding becoming bored and lethargic: 'I hate not doing anything, I get bored easily... (I like) a busy life ... I [like] to plan and keep occupied' (P1). Alternatively, passing the course and having careerfocused goals motivated other students: 'I want to pass the course ... I can put (the CCL) on my C.V. and get a good job. If you don't pass the course ... it's just a waste of your own time' (P15), and 'I want to be a ... special needs assistant ... so if I say, here's my certificate ... they can't turn me down, so basically to do what I love' (P8).

During learning: the performance phase. From a Vygotskian (1978) perspective, the processes of monitoring and motivating oneself cannot be understood apart from the environment in which it appears. Here, the environment is understood in an encompassing way so that it includes the physical environment, the historical and the cultural surroundings, as well as the more internal aspects of the learner's prior beliefs relevant to that moment (Stuckey, 1990). Although the first stage of SRL (before learning) has a focus on the regulatory processes of the self, the second stage of self-regulation (the performance phase, i.e., what happens during the learning act) highlights the interaction of the individual and the environment. In this study, it emerged that students learnt collectively by forming a 'community of practice' (Lave and Wenger, 1991) in which learning unfolded through collaboration, negotiation, discussion and dialogue. It can be advanced, therefore, that there are many 'teachers' who collectively create meaning; these are placed inside and outside the college environment, as well as at home and in the workplace. For example, students learned through:

- classroom discussions and debates: 'I'd put my point across and then there's a whole big debate thing about it and everyone starts joining in' (P9);

- group work: 'group work was good for putting our ideas together ... like a jig-saw' (P16);

- dialogue with their parents / guardians: 'my $D a \ldots$ and my Ma would explain things in English and Maths. My Da, he'd say: you can do it. You have the strength in you. So that's where I got my confidence from' (P8);

- college mentors: 'you ask them for advice if you are having any problems with your learning. . . . it's kind of like a friendship as well; someone who can help you out at work or college or both.' (P13);

- situational and contextual learning (see Brown, Collins and Duguid, 1989; Lave and Wenger, 1991) for example, in the workplace: '(in work) I learned all about hygiene, I learned it the hard way... I learned 
how to work with others... I also learned to be in time for work and to work by myself' (P11).

These and other sociocultural influences, such as being exposed to a number of 'powerful' teaching and learning strategies (Zimmerman, 2002), affect the way students control their own deliberate actions regarding selfregulation. In the context of the CCL programme, a variety of teaching strategies are used by the current author; these include audio-visual instruction such as: brainstorming (Osborn, 1953), concept mapping (Novak and Cañas, 2006) and mind-mapping (Buzan, 1996), mnemonics (see Scruggs and Mastropieri, 2000) and PowerPoint presentations. These strategies are now presented in turn.

Brainstorming. The process of Brainstorming is a strategy used to generate words and ideas in relation to a topic and encourages learners to participate in an active and animated way in response to a particular question. The process begins with a topic to be explored: each participant is encouraged to call out a word relevant to the topic in question and all responses are graphed and/or written (by the tutor and/or students) onto a large piece of paper (see Picture 1). For this following student, the process begins when the tutor draws a picture of an exploding head

and then there's a brainstorm ... we'd shout all of these ideas ... about a certain topic, so say if your topic is 'college', then someone would (shout) travelling, students, freebies, whatever, all that kind of thing ... and you can discuss them ... if they're on the board you don't have to try and think in your head (P5)

Concept mapping and mind mapping. Concept maps (referred to by CCL students as 'Spidergrams') is a visual strategy and takes the form of a diagram with lines and circles so information can be organised to make it is easier to

\section{Picture 1: Brainstorming - exploding head}

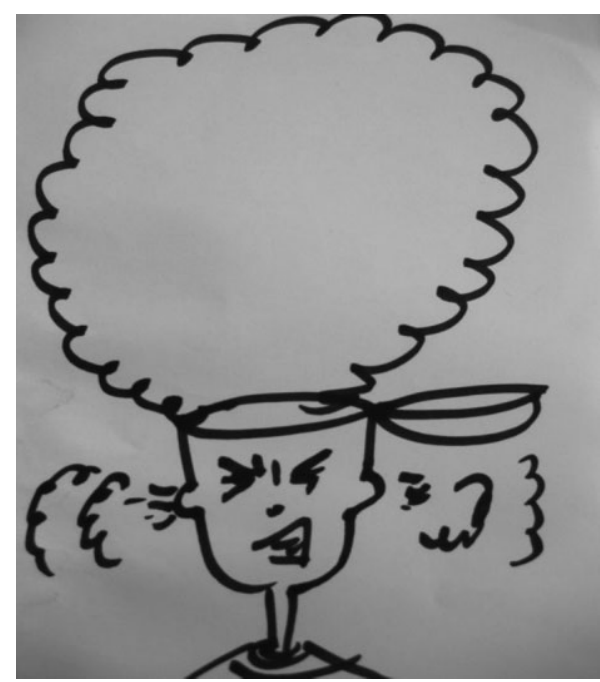

use or remember. Mind maps are similar to concept maps but use words, images and colour and typically take the form of branches like a tree or a network of connecting roads.

On the certificate programme, concept mapping and mind mapping are used to organise, visually structure and memorise the 'disconnected' words generated by brainstorming. The following student's comments show how she used a brainstorming exercise for generating her thoughts before progressing onto a Spidergram to put structure to these thoughts. For her, there was a progression from initially learning about something through brainstorming: 'if I was learning about it for the first time, (I'd use) the Brainstorm' (P5), to progressing onto a Spidergram to organise these thought and ideas: 'but then when you've learnt about it I'd do the Spidergram' (P5). Another student observed that mind maps can be more effective because each branch can be coloured differently. In this way, the information contained in a colour-coded mind map can be memorised better: 'just put a bit of colour in it . . it's easier to remember . . . When I highlight (the branches) . . it jumps out at me more and I can remember the information' (P16).

Mnemonics. In conjunction with brainstorming and Spidergrams, the use of mnemonics (see Scruggs and Mastropieri, 2000) proved to be an effective memory strategy in assisting learners to remember factual information. The mnemonic strategy called 'the letter strategy' (Mitchell, 2008, p. 141) prompts learners to remember a list of letters that form an acronym. Students are taught how to construct nonsense mnemonics to remember either a spelling (such as 'Arithmetic'- A Rat In The House May Eat The Ice Cream), or how to use 'chunking' in order to remember a larger piece of information. For example, the following student explains how she remembered facts on Caravaggio's life: 'we took out a key-word from each (paragraph) . . and we chunked them together . . his date of birth: 157/31/6 10 . . Italy/Rome/ Malta - Killed/Prison/Died' (P2). Finally, using visual imagery mnemonics was also very effective in drawing a student's attention to the power of associating visual images with verbal constructs: Figure 1 shows an example of one student's unique way of memorising the word dictionary.

PowerPoint presentations. In the context of the CCL programme, PowerPoints consist of a number of individual slides that contain three to four words and a small number of

Figure 1: A Visual Mnemonic of the Word 'Dictionary'
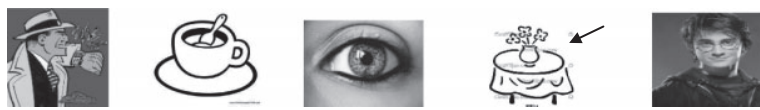

dic -

$$
\mathrm{t}
$$

on

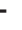

ary 
supporting visual images. This medium is frequently used by this author when introducing a new topic or theory, or to encourage debate and discussion in class. Although the benefit of PowerPoint has been contested (Savoy, 2009; Tufte, 2003), for certificate students, however, it is a valuable prop for learning: it supports those students whose learning style is strongly visual and/or auditory, and if used appropriately, can also be a useful tool for encouraging cognitive and metacognitive learning strategies. According to this learner: '(with PowerPoint) you can see the words visually and can see pictures... if you don't see the words and the pictures ... you're kind of lost, and you're wondering what (the lecturer) is going on about' (P13). Students also appreciated a printout of the PowerPoint, which enabled learners to 'go home and read over' (P1) what was covered on the day and be able to talk about it with their peers.

After learning: the self-reflection phase. The self-reflection phase processes consist of the process of self-evaluation completed by students in the form of journal keeping. This process is informed by an adaption of Honey and Mumford's (2000) learning cycle; a 'typical' student's written entry in a journal page would consist of a daily record that

- describes what happened in class;

- reflects on what was covered, and

- expresses affect, i.e., emotional responses to the learning situation.

For this student it was easier to have the above structure because:

it makes it less difficult ... we know that ... first we do this, then we do that, and then we do that ... and at the end ... what did you not enjoy? Sometimes I like all of the stuff I did, and some of the classes I like three-quarters of the things I did. (PI)

For other learners, the self-reflection process was a useful way to encourage: (1) self-improvement: 'if we do things a certain way and then you can think back and (see) if we could have done that better, or have done it differently' (P9); (2) memorisation: 'it's good to keep a (learning) journal so you know that when you come back to it a couple of hours later you say oh, I remember doing this' (P3), and (3) satisfaction: '(self-reflection) makes you look back and say well I'm happy I've done that today' (P4).

Finally, self-reflection also involves engaging with one's emotions during the act of learning (e.g., Schutz and DeCuir, 2002). Results show that academic emotions are significantly related to student motivation, learning strategies, cognitive resources, self-regulation and academic achievement (Pekrun et al., 2002). For this student, being in touch with his emotions was cathartic. He explained:

If you're coming in and you're all stressed out and you're under pressure like, you wouldn't be able to take in the information ... you'd be all in a panic... It's better to leave all those feelings at home. (P6)

\section{Discussion}

This study has used student voice to gain a deeper understanding of the learning process and outlined the teaching strategies that promoted autonomy and engagement of college students with ID. Although the active engagement of students' voice in research has been a practice in the field of school-based enquiry in the United States (Levin, 1994; Weis and Fine, 1993), the United Kingdom (Fielding and Bragg, 2003; Flutter and Rudduck, 2004) and Ireland (Flynn et al., 2012; Shevlin and Rose, 2008), the practice of using the voice of students with ID in higher education is a relatively new phenomenon. For Holdsworth (2000, p. 355), having and articulating a voice suggests having a 'legitimate perspective and opinion ... and/or having an active role in decisions about and implementation of educational policies and practices'. Robinson and Taylor (2007, p. 10) propose that the use of student voice "empowers students to have the opportunity to participate meaningfully and collaboratively in school improvement work'. By extension, the use of student voice in higher education ought to be fundamental to the development of an inclusive college environment. Such an environment should possess a culture of listening that is purposeful and significant; in other words, the experience needs to be authentic rather than tokenistic and should generate an element of change or transformative action as appropriate.

There are, however, a number of important issues that need to be considered in using student voice strategies as it is not a simple undertaking, nor is it easy and straightforward. MacBeath et al. (2003, p. 42) have criticised the flawed nature of research where only the 'more articulate ... are more likely to shape the decisions of their peers and to be "heard" by their teachers - leaving others, ironically, feeling disenfranchised in an initiative specifically designed to empower them'. Another concern raised by Flutter (2007) about the use of pupil voice is that it may undermine teachers' authority and has the potential to change the power relationships that exist between students and their teachers; this in turn may also lead to 'unlocking a barrage of criticism of them and their teaching' (Rudduck and Flutter, 2003, p. 75).

In spite of these concerns, however, the evidence from research in pupil voice shows that constructive criticism can have a profound impact on teaching practice, allowing teachers to reassess pupils and their capabilities. With regard to this current study, the use of voice was an important element in understanding the complexities of the learning process for college students with ID and the teaching strategies they found most helpful. For example, students valued process-oriented instruction facilitated through the use of dialogue and discussion, as well as 
audio and visual stimuli in the form of PowerPoints, brainstorming and concept/mind mapping. Learners also appreciated teaching instruction that stimulated the learning process as a thinking activity, one that explicated the process of learning instead of conceiving it simply as the memorisation and reproduction of facts. This process was most evident in the practice of SRL where students engaged with the 'before, during and after' stages of learning.

Finally, participants of the research valued opportunities for learning and peer collaboration in a safe and supportive learning climate.

\section{Conclusion}

The results and discussion section offers some valuable insights into students' experiences of learning and their perceptions of effective teaching strategies. There is clear evidence that students recognise the value of a learning environment that supports diversity and multiple ways of learning. Given the inherent limitation of the study sample, some tentative findings are offered as a basis for a more in-depth exploration of this emerging critical issue both within schools and in systems of higher education. In comparison with other studies (e.g., Paakkari, Tynjälä and Kannas, 2011; Säljö, 1979), there is evidence that the learning experiences of college students with ID are as complex and as multifaceted as any other college student; these voices offer valuable insights into how pedagogical practices can be informed. Further research could investigate how children with ID, their parents and teachers can come together to become proactive in fostering ways to succeed and survive in inclusive environments in secondary and post-secondary education. In this way students can develop a sense of their own identity as learners (Flutter and Rudduck, 2004) and teachers can embrace new perspectives on their teaching, enhance their pedagogies (Rudduck and McIntyre, 2007), reappraise their attitudes to inclusion and develop their professional knowledge (see Shevlin, Winter and Flynn, 2013).

Irish policy and provision in relation to inclusion is in a transitional phase as legislation mandating the development of inclusive learning environments has yet to be fully embedded in schools (Shevlin et al., 2013). If inclusive practices are to become the norm within primary, secondary and post-secondary systems of education, there is a need to reappraise the potential of students' voice in transforming our understanding of both student learning and the reservations that teachers possess about inclusion in practice. In this way, the potential to build more reciprocal relationships in the classroom is possible, one that equally values both students' voices and teachers' voices. As Lincoln (1995, p. 93) stated: '. . .the achievement of voice is mutual, and teachers who help students to find their voices will discover that their own voices are clearer and stronger in the process'.

\section{Acknowledgements}

The author wishes to acknowledge the students and co-researchers whose participation made the study possible.

Address for correspondence

John Kubiak,

National Institute for Intellectual Disability,

Trinity College Dublin,

3 College Green, Dublin 2,

Ireland.

Email:kubiakj@tcd.ie

\section{References}

Åkerlind, G. S. (2005) 'Variation and commonality in phenomenographic research methods.' Higher

Education research \& Development, 24 (4), pp. 321-34.

Barnes, C. (2004) 'Reflections on doing emancipatory disability research.' In J. Swain, S. French, C. Barnes \& C. Thomas (eds), Disabling Barriers - Enabling Environments. (2nd edn), pp. 47-53. London: Sage Publications.

Björnsdóttir, K. \& Svensdóttir, A. S. (2008) 'Gambling for capital: learning disability, inclusive research and collaborative life histories.' British Journal of Learning Disabilities, 36, pp. 263-70.

Black, P., Harrison, C., Lee, C., Marshall, B. \& Wiliam, D. (2002) Working inside the Black Box: Assessment for Learning in the Classroom. London: NfER/Nelson.

Brown, J. S., Collins, A. \& Duguid, P. (1989) 'Situated cognition and the culture of learning.' Educational Researcher, 18 (1), pp. 32-42.

Buzan, T. (1996) The Mind Map Book: How to Use Radiant Thinking to Maximize Your Brain's Untapped Potential. New York: Penguin.

Chadwick, D. D., Finlay, F., García Irarte, E., Greene, S., Harrington, J., Lawlor, A., Mannan, H., McConkey, R., O’Brien, P., Spain, J. \& Turner, A. (2010) Family Voices: Life in Ireland for Families of People with Intellectual Disabilities. National Institute for Intellectual Disability, Trinity College Dublin.

Chappell, A. (2000) 'The emergence of participatory methodology in learning disability research: understanding the context.' British Journal of Learning Disabilities, 28 (1), pp. 38-43.

Cooper, P. \& McIntyre, D. (1996) Effective Teaching and Learning: Teachers and Students' Perspectives. Buckingham, PA: Open University Press.

de los Reyes, E. \& Gozemba, P. A. (2002) Pockets of Hope: How Students and Teachers Change the World. Westport, CT: Greenwood Publishing Group.

Dart, B., Burnett, P. C., Purdie, N., Boulton-Lewis, G., Campbell, J. \& Smith, D. (2000) 'Influences of 
students' conceptions of learning and the classroom environment on approaches to learning.' Journal of Educational Research, 93, pp. 262-72.

Dorman, J. (2002) 'Classroom environment research: progress and possibilities.' Queensland Journal of Educational Research, 18 (2), pp. 112-40.

Fielding, M. (2004) 'Transformative approaches to student voice: theoretical underpinnings, recalcitrant realities.' British Educational Research Journal, 30 (2), pp. 295-311.

Fielding, M. \& Bragg, S. (2003) Students as Researchers: Making a Difference. Cambridge: Pearson Publishing.

Flinders University (2011) 'Up the hill project'. <http:// www.flinders.edu.au/sohs/sites/disability-studies/ associated-programs/up-the-hill-project---flinders -university.cfm> (accessed 5 December 2015).

Flutter, J. (2007) 'Teacher development and pupil voice.' The Curriculum Journal, 18 (3), pp. 343-54.

Flutter, J. \& Rudduck, J. (2004) Consulting Pupils: What's in It for Schools? London: RoutledgeFalmer.

Flynn, P., Shevlin, M. \& Lodge, A. (2012) 'Pupil voice and participation: empowering children with emotional and behavioural difficulties.' In T. Cole, H. Daniels \& J. Visser (eds), Routledge International Companion to Emotional and Behavioural Difficulties. pp. 253-60. London: Routledge.

Foucault, M. (1980) L. Marshall, J. Mepham \& K. Soper (eds), Power/Knowledge: Selected Interviews and Other Writings, 1972-1977. New York: Pantheon Books.

Hart, D., Grigal, M., Sax, S., Martinez, D. \& Will, M. (2006) 'Postsecondary education options for students with intellectual disabilities.' Research to Practice, 45, pp. $1-5$.

Hart, R. A. (1992) Children's Participation: From Tokenism to Citizenship. Florence, Italy: UNICEF International Child Development Centre. (Innocenti Essays; No 4; No inness 92/6).

Holdsworth, R. (2000) 'Schools that create real roles of value for young people.' Prospects, Quartely of Education, 3, pp. 349-62.

Honey, P. \& Mumford, A. (2000) The Learning Styles Helper's Guide. Maidenhead, England: Peter Honey Publications Ltd.

Kirshner, B. \& O'Donoghue, J. (2001) Youth - Adult Research Collaborations: Bringing Youth Voice and Development to the Research Process. Paper presented at the Annual Meeting of the American Educational Research Association, Seattle, WA, April 10-14.

Kubiak, J. (2013) Intellectually Disabled Students' Experiences of Learning in Tertiary Education: An Inclusive Phenomenography. Unpublished D.Ed. Thesis, Trinity College Dublin.

Kubiak, J. \& Espiner, D. (2009) 'Pushing the boundaries of inclusion within third level education.' The Frontline of Learning Disability, 74, pp. 8-9.
Lave, J. \& Wenger, E. (1991) Situated Learning: Legitimate Peripheral Participation. Cambridge: Cambridge University Press.

Levin, B. (1994) 'Educational reform and the treatment of students in schools.' Journal of Educational Thought, 28 (1), pp. 88-101.

Lincoln, Y. (1995) 'In search of students' voices.' Theory Into Practice, 34 (2), pp. 88-93.

MacBeath, J., Demetriou, H., Rudduck, J. \& Myers, K. (2003) Consulting Pupils: A Toolkit for Teachers. Cambridge: Pearson Publishing.

Marton, F. \& Booth, S. (1997) Learning and Awareness. Mahwah, MJ: Lawrence Erlbaum Associates.

Marton, F. \& Tsui, A. B. M. (2004) Classroom Discourse and the Space of Learning. Mahwah, MJ: Lawrence Erlbaum Associates.

Mitchell, D. (2008) What Really Works in Special and Inclusive education. Using Evidence-Based Teaching Strategies. London: Routledge.

National Institute for Intellectual Disability. (2010) All We Want to Say - 2nd Part. People with Intellectual Disabilities Presenting Research Findings in Ireland. Dublin: Trinity College Dublin.

Novak, J. D. \& Cañas, A. J. (2006) 'The Theory Underlying Concept Maps and How to Construct and Use Them.' Institute for Human and Machine Cognition. <http://cmap.ihmc.us/Publications/ ResearchPapers/TheoryCmaps/TheoryUnderlying ConceptMaps.htm> (accessed 24 November 2008).

O'Brien, P., O'Keeffe, M., Kenny, M., Fitzgerald, S. \& Curtis, S. (2008) Inclusive education: A tertiary experience and transferable model? Lessons learned from the Certificate in Contemporary Living Programme: Dublin: National Institute for Intellectual Disability, TCD, No 3, Monograph series, pp. 1-97.

O'Connor, B., Kubiak, J., Espiner, D. \& O'Brien, P. (2012) 'Lecturer responses to the inclusion of students with intellectually disabilities auditing undergraduate classes.' Journal of Policy and Practice in Intellectual Disabilities, 9 (4), pp. 247-56.

Osborn, A. (1953) Applied Imagination: Principles and Procedures of Creative Problem Solving. New York: Charles Scribner's Sons.

Paakkari, L., Tynjälä, P. \& Kannas, L. (2011) 'Critical aspects of student teachers' conceptions of learning.' Learning and Instruction, 21, pp. 705-14.

Pedder, D. \& McIntyre, D. (2004) 'The impact of pupil consultation on classroom practice.' In M. Arnot, D. McIntyre, D. Pedder \& D. Reay (eds), Consultation in the Classroom: Developing Dialogue about Teaching and Learning. pp. 7-43. London: Pearson Publishing.

Pekrun, R., Goetz, T., Titz, W. \& Perry, R. P. (2002) 'Academic emotions in students' self-regulated learning and achievement: a programme of qualitative and quantitative research.' Educational Psychologist, 37 (2), pp. 91-105. 
Reason, W. \& Bradbury, H. (2006) Handbook of Action research. (2nd edn). Thousand Oaks, CA: Sage Publications.

Rix, J., Hall, K., Nind, M., Sheehy, K. \& Wearmouth, J. (2009) 'What pedagogical approaches can effectively include children with special educational needs in mainstream classrooms? A systematic literature review.' Support for Learning, 24 (2), pp. 86-94.

Robinson, C. \& Taylor, C. (2007) 'Theorising student voice: values and perspectives.' Improving Schools, 10 (1), pp. 5-17.

Rose, R. \& Shevlin, M. (2010) Count Me In! Ideas for Actively Engaging Students in Inclusive Classrooms. London: Jessica Kingsley Publishers.

Rudduck, J. \& Flutter, J. (2003) How to Improve your School: Giving pupils a Voice. London and New York: Continuum Press.

Rudduck, J. \& McIntyre, D. (2007) Improving Learning Through Consulting Pupils. Improving Learning TLRP Series. London: Routledge.

Saloviita, T. (2000) 'An inclusive adult education program for students with mild to severe developmental disabilities: A pilot project in Finland.' <http://www .steps-forward.org/research/search/?cx $=0171813238$ $31192321238 \% 3$ Aifsync9jo7c\&cof=FORID\%3A10 $\&$ ie $=U T F-8 \& q=$ steps + forward $+\&$ sa. $x=44 \&$ sa. $y=13>$ (accessed 5 December 2015).

Savoy, A. (2009) 'Information retention from PowerPoint and traditional lectures.' Computers and Education, 52 (4), pp. 858-67.

Säljö, R. (1979) Learning in the learner's perspective: I. Some common-sense conceptions. Reports from the Institute of Education. University of Gothenberg, 76, as summarized in Psychology: Theory and Application.

Schutz, P. A. \& DeCuir, J. T. (2002) 'Inquiry on emotions in education.' Educational Psychologist, 37 (2), pp. 125-34.

Scruggs, T. E. \& Mastropieri, M. A. (2000) 'The effectiveness of mnemonic instruction for students with learning and behaviour problems: an update and research synthesis.' Journal of Behavioural Education, 10, pp. 163-73.

Shevlin, M. \& Rose, R. (2008) 'Pupils as partners in education decision making: responding to the legislation in England and Ireland.' European Journal of Special Needs Education., 23 (4), pp. 423-30.

Shevlin, M., Winter, E. \& Flynn, P. (2013) 'Developing inclusive practice: teacher perceptions of opportunities and constraints in the Republic of Ireland.' International Journal of Inclusive Education, 17 (10), pp. 1119-33.

Stuckey, S. (1990) Situated cognition: A strong hypothesis. A paper presented at the NATO Advanced Research workshop, Cognitive modelling and interactive environments.

Topping, K. J. (2001) Peer Assisted Learning: A Practical Guide for Teachers. Brookline, MA: Brookline Books.

Traustadóttir, R. (2006) 'Fötlunarrannsóknir: Á herslur óg alitamal í rannsóknum með fótluðu fólki [Disability research: New emphasis and challenges in researching with disabled people], cited in Björnsdóttir, K., and Svensdóttir, A.S., (2008) Gambling for capital: learning disability, inclusive research and collaborative life histories.' British Journal of Learning Disabilities, 36, pp. 263-70.

Tufte, E. R. (2003) The Cognitive Style of PowerPoint. Cheshire, CT: Graphics Press.

Turnbull, P., Friesen, B. J. \& Ramirez, C. (1998) 'Participatory action research as a model for conducting family research.' Research and Practice from Persons with Disabilities, 23 (3), pp. 178-88.

Uditsky, B. \& Hughson, E. (2012) 'Inclusive postsecondary education - an evidence-based moral imperative.' Journal of Policy and Practice in Intellectual Disabilities, 9 (4), pp. 298-302.

United Nations (2006) Convention on the Rights of Persons with Disabilities. New York: United Nations.

University of Alberta. (2006) 'On campus program.' $<$ http://www.oncampus.ualberta.ca/Program Description.aspx> (accessed 5 December 2015).

UNESCO (1994) The Salamanca Statement and Framework for Action on Special Needs Education. Paris: UNESCO.

Vygotskian, L. S. (1978) Mind in Society: The Development of Higher Psychological Processes. Cambridge, MA: Harvard University Press.

Walmsley, J. \& Johnson, K. (2003) Inclusive Research with People with Intellectual Disabilities: Past, Present and Futures. London: Jessica Kingsley.

Weis, L. \& Fine, M. (eds) (1993) Beyond Silenced Voices: Class, Race, and Gender in United States Schools. Albany, NY: State University of New York Press.

Zimmerman, B. J. (2002) 'Becoming a self-regulated learner: an overview.' Theory Into Practice, 21 (2), pp. 64-70. 